\title{
The effect of orientated electric fields on biologically relevant iron-sulfur clusters: Tuning redox reactivity for catalysis
}

\author{
Samuel J H Gaughan ${ }^{a, b}$, Jonathan D Hirst*a , Anna K Croft ${ }^{* b}$ and Christof M Jäger*b \\ ${ }^{a}$ School of Chemistry, University of Nottingham, University Park, Nottingham NG7 2RD, United \\ Kingdom \\ ${ }^{\mathrm{b}}$ Department of Chemical and Environmental Engineering, Faculty of Engineering, University of \\ Nottingham, University Park, Nottingham NG7 2RD, United Kingdom
}

\begin{abstract}
Enzyme-based iron-sulfur clusters, exemplified in families such as hydrogenases, nitrogenases and radical $S$-adenosylmethionine enzymes, feature in many essential biological processes. The functionality of biological iron-sulfur clusters extends beyond simple electron transfer, relying primarily on the redox activity of the clusters, with a remarkable diversity for different enzymes. The active site structure and the electrostatic environment in which the cluster resides direct this redox reactivity. Orientated electric fields in enzymatic active sites can be significantly strong and to understand the extent of their effect on iron-sulfur cluster reactivity can inform first steps towards rationally engineering their reactivity. An extensive systematic density functional theory based screening approach using OPBE/TZP has afforded a simple electric field effect representation. The results demonstrate that the orientation of an external electric field of strength $0.288 \mathrm{MV} \mathrm{cm}^{-1}$ at the centre of the cluster can have a significant effect on its relative stability in the order of $35 \mathrm{~kJ} \mathrm{~mol}^{-1}$. This shows clear implications for the reactivity of iron-sulfur clusters in enzymes. The results also demonstrate that the orientation of the electric field can alter the most stable broken symmetry state, which further has implications on the directionality of initiated electron transfer reactions. These insights open the path for manipulating enzymatic redox reactivity of ironsulfur cluster containing enzymes by rationally engineering orientated electric fields within the enzymes.
\end{abstract}


Keywords: Density functional theory, enzymes, iron-sulfur clusters, oriented electric fields, radical S-adenosylmethionine.

TOC:

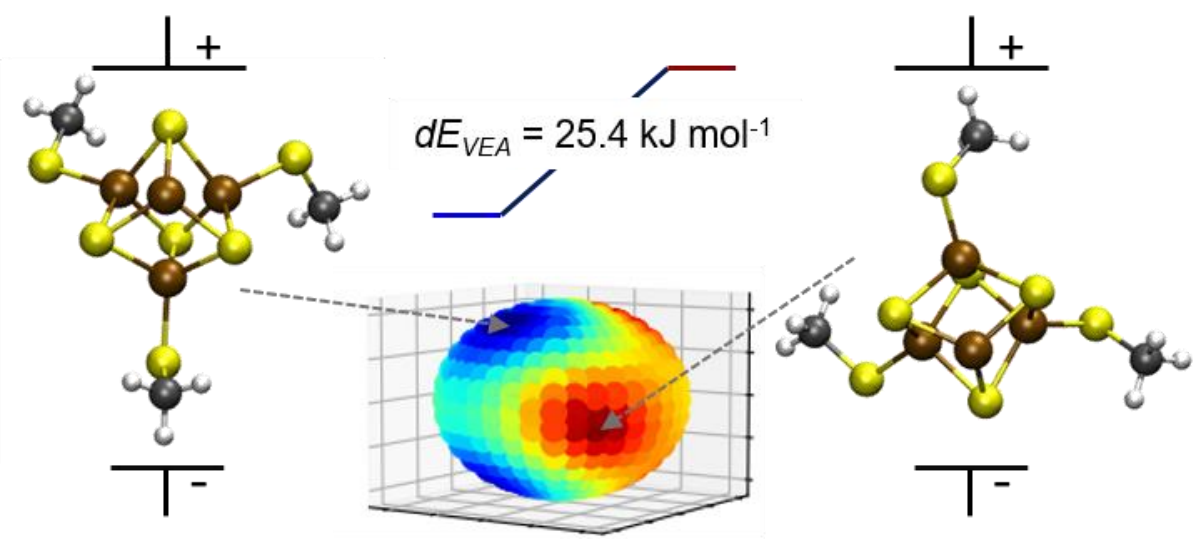




\section{Introduction}

Iron-sulfur clusters play a critical role in the reactions catalysed by several families of enzymes, providing a wide variety of functions in each. Their possible role in enabling the emergence of early life ${ }^{1}$ and capacity to perform many different roles within enzymatic pathways ${ }^{2,3}$ has led to them being characterised as "one of the most ubiquitous and functionally versatile prosthetic groups in nature". The discovery and purification of ferredoxins in 1962 was an early indication that iron could play roles in enzymes in addition to its well-known presence in hemoproteins. ${ }^{5}$ Both iron and iron-sulfur clusters act primarily as mediators for electron transfer with the ability to be either the source or sink for electrons in redox reactions, and iron-sulfur clusters are extremely useful for electron transport due to the delocalisation of electron density across the cluster. ${ }^{6,7}$ The mediator role is one of the most common functions of iron-sulfur clusters, found in a variety of enzymes including those that couple proton transfer to electron transport, such as [FeFe] hydrogenases, which possess a unique version of an iron-sulfur cluster featuring a diiron centre and a bridging dithiolate. ${ }^{8,9}$ Many enzymes containing iron-sulfur clusters use $[2 \mathrm{Fe}-2 \mathrm{~S}],[4 \mathrm{Fe}-4 \mathrm{~S}]$ and $[3 \mathrm{Fe}-4 \mathrm{~S}]$ structures in both redox and non-redox functions. For example, radical $S$-adenosylmethionine (rSAM) enzymes make use of a $[4 \mathrm{Fe}-4 \mathrm{~S}]$ cluster to reductively cleave $S$-adenosylmethionine (SAM) into methionine and 5'deoxyadenosyl radical, the latter of which is used to initiate a variety of radical reactions that have been reviewed previously. ${ }^{10,11,12,13}$ In some cases, electron transfer may be an intermediate step rather than the complete function of an enzyme, such as the case of the biotin synthase rSAM mechanism where the FeS clusters mediate the donation of a sulfur atom. ${ }^{14}$

Redox activity is an important property in enzymes. Reengineering this property has been the focus of experimental studies for many families of enzymes, including the antioxidant peroxiredoxins,${ }^{15}$ thioredoxins, particularly those that act as electron donors for other enzymes, ${ }^{16}$ and kinases, ${ }^{17}$ amongst other more general studies focused on control via thiol/disulfide exchange, ${ }^{18,19}$ 
enzyme orientation ${ }^{20}$ and substrate specificity. ${ }^{21}$ Additionally, redox activity has been used to probe mechanism, ${ }^{22,23,24,25,26}$ to understand the effect of changing iron-sulfur cluster ligands on the redox potential, ${ }^{27}$ to assess stability and reactivity of the cluster, ${ }^{28}$ and to guide improvements in enzyme activity with directed evolution. ${ }^{29}$

Redox reactions, often studied and used via electrochemical methods, ${ }^{30,31,32}$ are sensitive to electric fields. This alone would motivate an analysis of the electrostatic environment generated by an enzyme containing an iron-sulfur cluster. However, electrostatics also play a role in enzyme catalysis in general, ${ }^{33}$ including protein-protein interactions, ${ }^{34}$ conformational motions, ${ }^{35}$ and catalysis. ${ }^{36,37}$ Electrostatic preorganisation in the active site of enzymes, and the electrostatic stabilisation associated with this, are a more recent area of study. ${ }^{38}$ This preorganisation has also been quantified computationally. ${ }^{39,40}$ Computational methods such as molecular dynamics simulations, density functional theory (DFT), Valence Bond Theory and Poisson-Boltzmann Equation (PBE) Solvers have advanced our understanding of the role of electrostatics in enzyme catalysis, ${ }^{41,42,43}$ providing a more complete picture of the function of enzymes such as alpha-amylase, ${ }^{44}$ methyltransferases ${ }^{45}$ and QueE. ${ }^{46}$ These methods have also been used to study specific properties such as the contribution of individual amino acids to the overall electrostatic field of a protein, ${ }^{47}$ electrostatic steering and channeling, ${ }^{48,49}$ and the direct effect of the electrostatic field on catalytic rate. $^{50}$

Direct study of electric fields in the context of manipulating catalysis is a growing area of research. A recent review highlighted oriented electric fields as reagents, as well as their effects on enzyme catalysis. ${ }^{51} \mathrm{DFT}$ as the QM method in a QM/MM approach has been used previously to study the effects of an electric field on biological chromophores ${ }^{52}$ and on enzymes. ${ }^{53}$ Studies have also been performed on iron-sulfur clusters in the context of enzymes to elucidate information about properties such as coordination, geometry, and electrostatics. These studies have used extended X- 
ray fine structure spectroscopy (EXAFS) and DFT, ${ }^{54}$ including the application of broken-symmetry $\mathrm{DFT}^{55}$ to iron-sulfur clusters to model antiferromagnetic coupling.

In this study, we directly and systematically investigate the impact of an external electric field on biologically relevant iron-sulfur clusters. We examine the fundamental effect of applying and reorienting a simple electric field on the stability and reactivity of selected model iron-sulfur clusters. The information on how an oriented electric field influences the reactivity of the clusters can later be combined with the knowledge and understanding of the contribution of individual amino acids to the electric field in an enzyme. This will allow bespoke control of iron-sulfur cluster reactivity and stability through mutations of the surrounding residues ${ }^{47}$ Consequences of these adaptations would include either the ability to improve existing reactions by increasing the rate of reaction, integrating oxygen tolerance, or exploiting enzyme selectivity for reactions that were previously only accessible through synthetic approaches.

\section{Methods}

Unrestricted geometry optimisation calculations using DFT were performed using the QChem software package ${ }^{56}$ and compared with literature values ${ }^{57}$ using the same model systems, featuring the iron-sulfur clusters $[2 \mathrm{Fe} 2 \mathrm{~S}]$ or $[4 \mathrm{Fe} 4 \mathrm{~S}]$ and four methanethiolate ligands bound to the iron atoms; two per iron or one per iron respectively (Figure 1). The geometry of a third cluster, identical to the $[4 \mathrm{Fe} 4 \mathrm{~S}]$ cluster but with one fewer methanethiolate ligands, was also optimised. The initial geometries were based on the crystal structure (PDB ID 1ZOY.) The hybrid OPBE functional, ${ }^{58,59}$ which consists of Handy's optimised exchange (OPTX) ${ }^{60}$ and $\mathrm{PBE}^{61}$ correlation, was used for both the geometry optimisations and further single point calculations. The use of this functional allows comparison with the work of Swart et al., ${ }^{57}$ and the spin states of iron complexes predicted are consistent with literature studies. ${ }^{62,63}$ The TZP basis set ${ }^{64,65,66}$ was chosen for both 
geometry optimisations and single point calculations to facilitate this comparison. Methods used by other groups include $\mathrm{B}(5 \% \mathrm{HF}) \mathrm{P} 86$ and a triple- $\zeta$ basis set with polarization functions for accurate bond covalency, ${ }^{67,68}$ and $\mathrm{B}(5 \% \mathrm{HF}) \mathrm{P} 86 / 6-311+\mathrm{G}(\mathrm{d})$ for the QM region of a QM/MM study into the protein environmental effects around iron-sulfur clusters. ${ }^{69}$ While those levels of theory would be suitable for optimisations, we chose OPBE/TZP because it demonstrates both the correct structural predictions and accuracy in the relative ranking of spin state energies which is particularly important for this study. ${ }^{70,71}$ The geometry optimisations were also repeated using the polarisable continuum model $\mathrm{COSMO}^{72}$ (Conductor-like screening model) with a dielectric constant of 4.0 to simulate a protein environment. ${ }^{73,74}$

We investigate the effect of an oriented external electric field on the vertical electron affinity (VEA) and the most stable state of the model systems by performing 1296 single point calculations in the presence of two external, equal but oppositely signed point charges, equidistant from the centre of mass of the system, whose bisector intersects this centre. The redox potential is an important property to consider when investigating the reactivity of iron-sulfur clusters. It is dependent on the stability difference of the oxidised and reduced state of the system and the reorganisation energy. The latter is influenced by the relaxation of the system upon electron transfer and the restructuring of environment, often dominated by solvent reorganisation. The VEA accounts for the energy difference between the oxidised and reduced state without any relaxation (Eqn 1) and can be taken as a first approximation for the reactivity difference of the two oxidation states.

$$
E_{V E A}=E_{o x}-E_{r e d},
$$

where $E_{V E A}$ is the VEA and is positive if the reduction of the oxidised state is energetically favourable, $E_{o x}$ is the total electronic energy of the oxidised state and $E_{r e d}$ is the corresponding energy of the reduced cluster with the oxidised cluster's geometry. 
The effect of the direction of the external electric field was investigated by rotating point charges defining the field about two axes in the system and mapping them onto a sphere around the model systems. The axes of rotation used to orient the field around the clusters are shown and labelled in Figure 1. The notation is described further in Supporting Information Section S2.
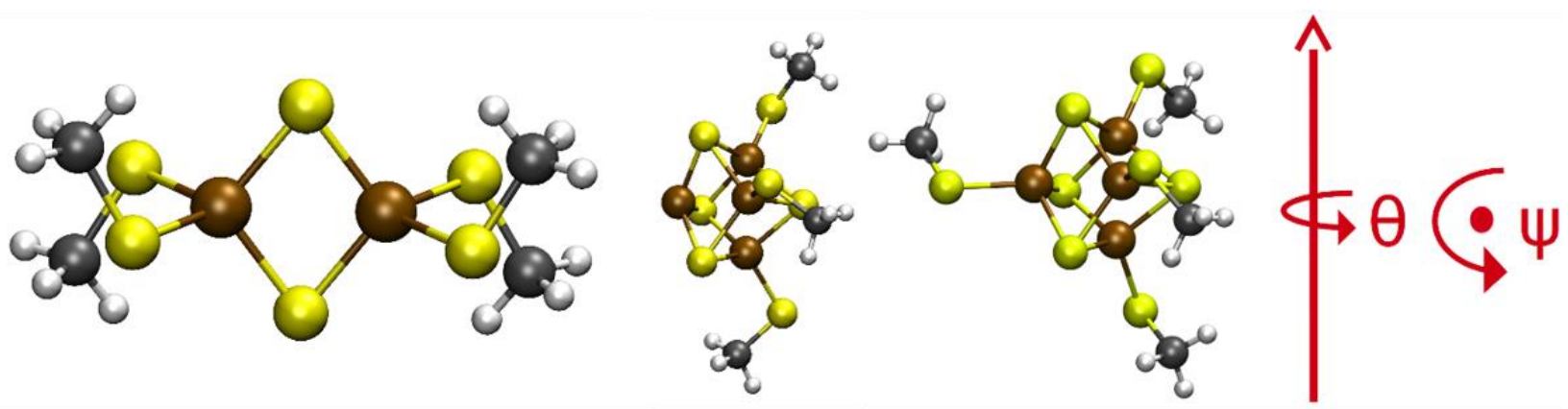

Figure 1: Definition of axes for the 2Fe2S, (left) labile 4Fe4S, (middle) and 4Fe4S (right) clusters. All geometries shown are optimised structures for the oxidised clusters at the OPBE/TZP level of theory in a vacuum.

The rotation of the electric field can be defined by rotations about these axes. Supporting Information Section S2 provides examples of how the point charges are positioned initially and their directions of movement for all rotations applied.

Systems containing atoms with multiple possible oxidation states can be described in several ways. The reduced state of the $2 \mathrm{Fe} 2 \mathrm{~S}$ cluster introduced earlier could have an oxidation state of +2.5 assigned to both iron atoms, a symmetrical description. In many cases however it is necessary to define broken symmetry states, where the additional electron is fully localised on one of the iron atoms, for systems with ferromagnetic and antiferromagnetic coupling, for example. ${ }^{75,76}$ This would be particularly important if a specific iron atom is involved in a reaction, as the oxidation state would likely affect the reactivity, or govern even whether the reaction would progress at all. There are two broken symmetry states for the $1 / 2$ total spin system where the formal oxidation states of the iron 
atoms of the $2 \mathrm{Fe} 2 \mathrm{~S}$ cluster are $+2 /+3$ and $+3 /+2$. A single point calculation using a default guess wavefunction for the $1 / 2$ total spin reduced cluster using one of the point charge positions will give one of the two broken symmetry states $+2 /+3$ and $+3 /+2$. By taking the final wavefunction from each of these situations and using them as guess wavefunctions in two calculations without point charges but preserving the orbital occupancies, we calculated two wavefunctions, one for each broken symmetry state, which do not have orbitals influenced by an external field. We used these wavefunctions as initial guesses when we added point charges, allowing us to see the full range of field effects for both broken symmetry states. Geometry optimisations and subsequent frequency calculations were performed in vacuum and using COSMO with a dielectric of 4.0 for the model $2 \mathrm{Fe} 2 \mathrm{~S}, 4 \mathrm{Fe} 4 \mathrm{~S}$ and labile $4 \mathrm{Fe} 4 \mathrm{~S}$ iron-sulfur clusters for the four reported spin states in each case. ${ }^{57}$

\section{Results and Discussion}

The energy relative to the calculated ground state for each system is reported in Table 1. All optimised geometries were confirmed as minima by frequency calculations. The only case where the ground state is not the low spin state is from the reference value for the reduced $2 \mathrm{Fe} 2 \mathrm{~S}$ cluster; this is not surprising as the $1 / 2$ and 9/2 spin states are isoenergetic. The geometry and frequency calculations for each spin state agree with the literature values, ${ }^{57}$ within $5 \mathrm{~kJ} \mathrm{~mol}^{-1}$ (Table 1) and are consistent in the relative stability of each state and can therefore be justified for use in the subsequent investigations for the purpose of determining relative stability and reactivity when a directed external electric field is applied. The optimisations in a COSMO environment were generally lower in energy but showed the same trends in stability as the vacuum environment. This is to be expected as prior work found that both PCM and COSMO approaches converge to very similar structures as the gas phase optimisation, although there were some exceptions. ${ }^{77}$ COSMO has also been used in the successful prediction of Mössbauer spectral parameters, ${ }^{78}$ reduction potentials ${ }^{79}$ and other properties of iron- 
sulfur clusters and similar molecules. ${ }^{80}$ Furthermore, experimental work has shown that the redox potential of biological iron-sulfur clusters is significantly dependent on the environment, when considering different enzymes, ${ }^{81}$ or modifying the ligands of the cluster. ${ }^{82}$ Optimisations on the labile 4Fe4S cluster can also be justified using the same reasoning and could be used for further study of a similar nature when investigating the behaviour of the cubane cluster where one iron atom is not bound to a ligand (for example SAM in the radical SAM enzyme superfamily). Using VEA as a surrogate for the redox potential is not a new approach but offers an approximation with the potential for high throughput, needed to systematically study an orientated electric field effect. Previous work has gone further to approximate redox potentials from DFT calculations by considering electronegativity, ${ }^{83}$ electrophilicity ${ }^{84,85,86}$ and combinations of properties ${ }^{87,88}$. While these methods would provide more experimentally comparable values, the VEA provides a sufficient description of the change in these properties and is straightforward to compute. This makes it feasible to investigate the effect of a rotating electric field via thousands of individual DFT calculations.

The relative energies are in good agreement with literature values obtained for these systems with the order of spin state stability preserved. Slight differences in the energies compared to literature are likely to originate from different implementations of the implicit solvent method (COSMO) and different convergence criteria in the used programmes but do not influence the qualitative agreement. Single point calculations were performed on the model iron-sulfur clusters in the presence of an electric field of varying orientation for the oxidised and reduced states. The optimised geometry of the ground state spin oxidised cluster was used in all cases to allow the calculation of the VEA. Figure 2 displays the effect of the rotation of the electric field on the energy of the two most stable $9 / 2$ and $1 / 2$ spin states of the reduced $2 \mathrm{Fe} 2 \mathrm{~S}$ model cluster about the principal axes presented in Figure 1. 
Table 1: Relative energies for OPBE/TZP geometry optimized model iron-sulfur clusters in different spin states, compared with literature values ${ }^{57}$ in both vacuum and within a COSMO environment using a dielectric of 4.0. Values presented in $\mathrm{kJ} \mathrm{mol}^{-1}$. All values correspond to geometry optimized structures at the given oxidation and spin state. Absolute energy values are presented in the Supporting Information (Table S1).

\begin{tabular}{|c|c|c|c|c|}
\hline $2 \mathrm{Fe} 2 \mathrm{~S}$ & \multicolumn{4}{|c|}{ Total spin, $\mathbf{S}$} \\
\hline Oxidised & $\mathbf{S}=\mathbf{0}$ & $S=1$ & $S=2$ & $S=5$ \\
\hline Reference & 0.00 & 54.34 & 104.21 & 72.64 \\
\hline Vacuum & 0.00 & 65.93 & 110.44 & 84.06 \\
\hline COSMO & 0.00 & 57.44 & 100.68 & 83.69 \\
\hline Reduced & $S=1 / 2$ & $S=3 / 2$ & $S=5 / 2$ & $\mathrm{~S}=9 / 2$ \\
\hline Reference & 0.67 & 84.11 & 100.57 & 0.00 \\
\hline Vacuum & 0.00 & 92.64 & 98.74 & 7.47 \\
\hline COSMO & 0.00 & 84.24 & 91.71 & 4.16 \\
\hline 4Fe4S & \multicolumn{4}{|c|}{ Total spin, $\mathbf{S}$} \\
\hline Oxidised & $\mathbf{S}=\mathbf{0}$ & $S=1$ & $S=2$ & $S=9$ \\
\hline Reference & 0.00 & 48.61 & 82.94 & 156.38 \\
\hline Vacuum & 0.00 & 45.99 & 81.33 & 177.29 \\
\hline COSMO & 0.00 & 44.85 & 79.85 & 181.25 \\
\hline Reduced & $S=1 / 2$ & $S=3 / 2$ & $S=5 / 2$ & $S=17 / 2$ \\
\hline Reference & 0.00 & 62.09 & 66.15 & 63.97 \\
\hline Vacuum & 0.00 & 59.64 & 66.13 & 74.39 \\
\hline COSMO & 0.00 & $50.65 *$ & 61.11 & 77.45 \\
\hline Labile $4 \mathrm{Fe} 4 \mathrm{~S}$ & \multicolumn{4}{|c|}{ Total spin, $\mathrm{S}$} \\
\hline Oxidised & $\mathbf{S}=\mathbf{0}$ & $S=1$ & $\mathbf{S}=2$ & $S=9$ \\
\hline Vacuum & 0.00 & 58.45 & 53.92 & 160.14 \\
\hline COSMO & 0.00 & 56.53 & 56.28 & 163.19 \\
\hline Reduced & $S=1 / 2$ & $\mathrm{~S}=3 / 2$ & $S=5 / 2$ & $S=17 / 2$ \\
\hline Vacuum & 0.00 & 64.99 & 45.80 & 66.36 \\
\hline COSMO & 0.00 & 56.28 & 46.79 & 58.52 \\
\hline
\end{tabular}

*) optimized state with one imaginary frequency. This state was not used in any further calculations. 
a)

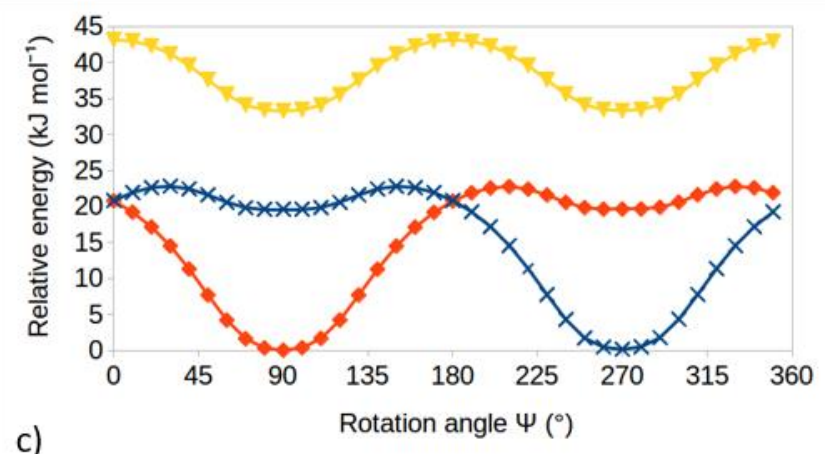

c)

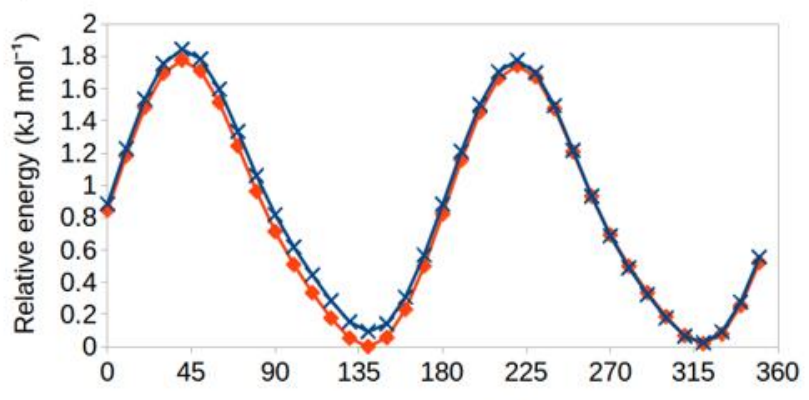

e)

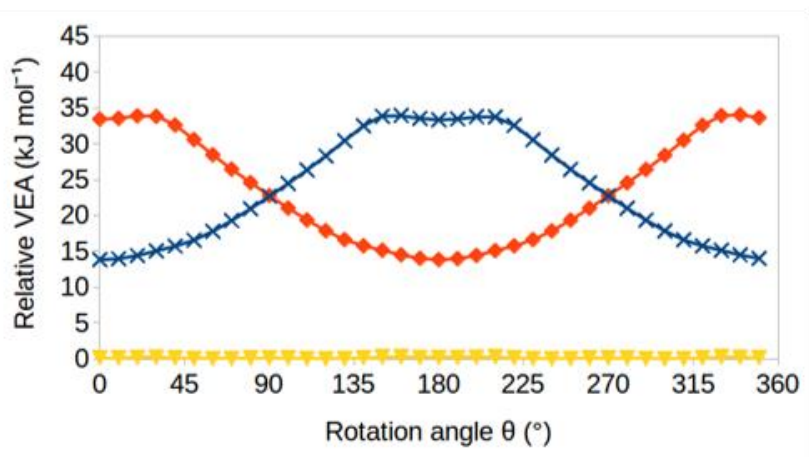

b)

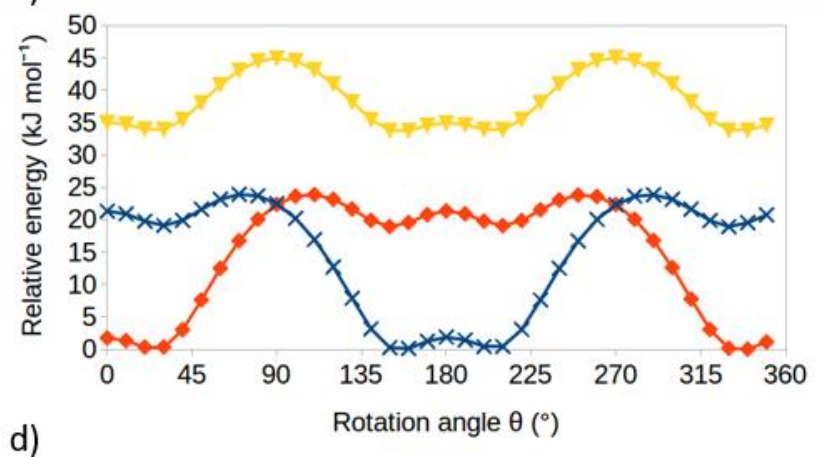

d)

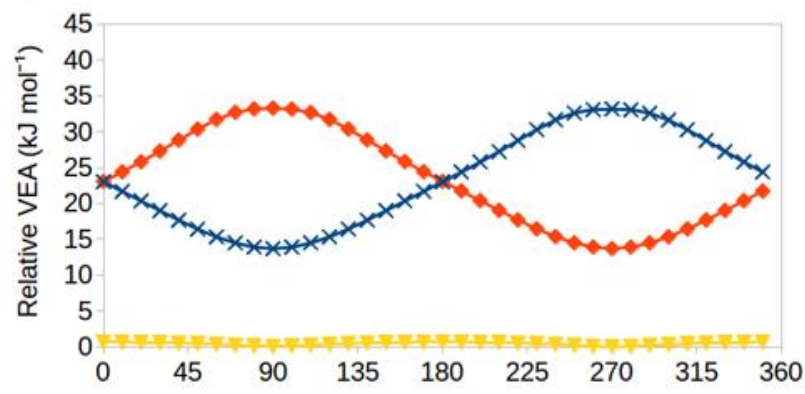

f)

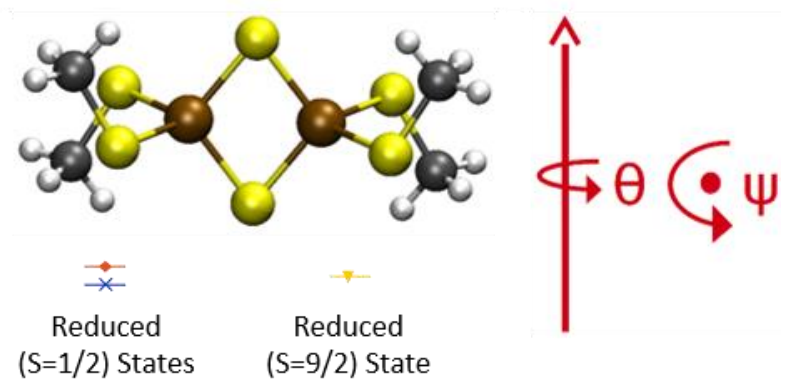

Figure 2: Relative energy profiles of the reduced $2 \mathrm{Fe} 2 \mathrm{~S}$ model cluster (a-c) and the VEA (d, e) of the same cluster with the orientation of an external electric field in the gas phase. Rotation angle indicates the rotation from the initial position of the field about the axis normal to the plane of the cluster $(\mathrm{a}, \mathrm{d})$, the $\mathrm{S}-\mathrm{S}$ axis $(\mathrm{b}, \mathrm{e})$ or the Fe-Fe axis $(\mathrm{c})(\psi \times \theta$ represents the rotation around the axis perpendicular to those shown in panel f)).

As can be seen from Figure 2, reorienting a directed electric field can influence the electronic stability of the $2 \mathrm{Fe} 2 \mathrm{~S}$ cluster significantly. Depending on the axis of rotation, the effect on the stability can vary up to $23 \mathrm{~kJ} \mathrm{~mol}^{-1}$ (in the case of rotating around the normal to the plane of the cluster, Figure 
$2 \mathrm{a}, \mathrm{b}, \mathrm{e}$ ) and down to only $1.8 \mathrm{~kJ} \mathrm{~mol}^{-1}$ (in the case of rotating around the FeFe axis, Figure $2 \mathrm{~d}$ ). Each spin state is influenced differently in relation to the field orientation, which leads to a varying energy gap between the spin states. However, this variation is never large enough to lead to the 9/2 spin state being the ground state (Figures 2a-c). When comparing the electric field effect between the gas phase (Figure 2a) and an implicit solvation with a low dielectric constant of 4.0 (Figure 2b), the observed effect is maintained, but the energy gap between the two spin states decreases slightly. Further results with implicit solvation are presented in Supporting Information Section S5.

Next, it was investigated how the electric field influences the stability of different broken symmetry states which showed a significant effect on the relative stability of those. When rotating the field around the Normal to the plane of the 2Fe2S cluster (Figures 2a-b), the most stable spin state flips when the field is exactly aligned along the S-S axis. This means that, depending on the orientation of an external electric field, the cluster adapts by adopting a different broken symmetry state. As these different states will show different reactivity in directed electron transfer, notably in relation to redox potential, ${ }^{73}$ they will also show different reactivity patterns with e.g., different substrates reacting with the cluster in an enzymatic active site. The rotation about the $\mathrm{Fe}-\mathrm{Fe}$ axis is diagrammatically presented in the Supporting Information (Figure S1) There is very little variation in VEA, with the value for the $1 / 2$ spin states remaining between about 22 and $23 \mathrm{~kJ} \mathrm{~mol}^{-1}$ and the $9 / 2$ spin state between 0 and $1 \mathrm{~kJ} \mathrm{~mol}^{-1}$.

The relationship between the stability of the oxidised and reduced clusters and the changes to the redox reactivity of the clusters are inferred from the VEA calculations for the cluster from the data presented above. Figure 2e depicts how the VEA varies with rotation about the Normal axis. Depending on the rotation axis, $\Delta E_{V E A}$ varies by up to $20 \mathrm{~kJ} \mathrm{~mol}^{-1}$. The results also suggest that the 9/2 spin state of the reduced cluster is unlikely to be involved in redox reactions as it is both less stable and has a lower electron affinity than both $1 / 2$ spin states. 
To extend this analysis of the principal axes of the $2 \mathrm{Fe} 2 \mathrm{~S}$ cluster, we systematically scanned the orientation of the electric field about multiple axes to create a 3-dimensional visualisation. Figure 3 depicts the analysis for the $2 \mathrm{Fe} 2 \mathrm{~S}$ cluster. To understand why a differently orientated electric field influences the stability and reactivity of the $2 \mathrm{Fe} 2 \mathrm{~S}$, we then matched these observations to the symmetry of the frontier orbitals of the reactive species.

The stability pattern observed for the principal axes' rotations described above is reflected in the analysis of the full rotations. When looking at the VEA, some electric field orientations show significantly higher reactivity compared to others. Considering the individual stabilities of the oxidised and reduced states one can further see the relation with the frontier orbital occupancies, as also depicted in Figure 3.

Looking at the differences for the two reduced broken symmetry spin states, the effect of the directed electric field is mirror symmetric for each state. The cluster is stabilised when the side with higher electron density of the HOMO is close to the positive charge defining the electric field. Due to the different orbital occupancy of the oxidised state (fully occupied HOMO) this species shows a higher symmetry in reference to the effect of the electric field. 
a)

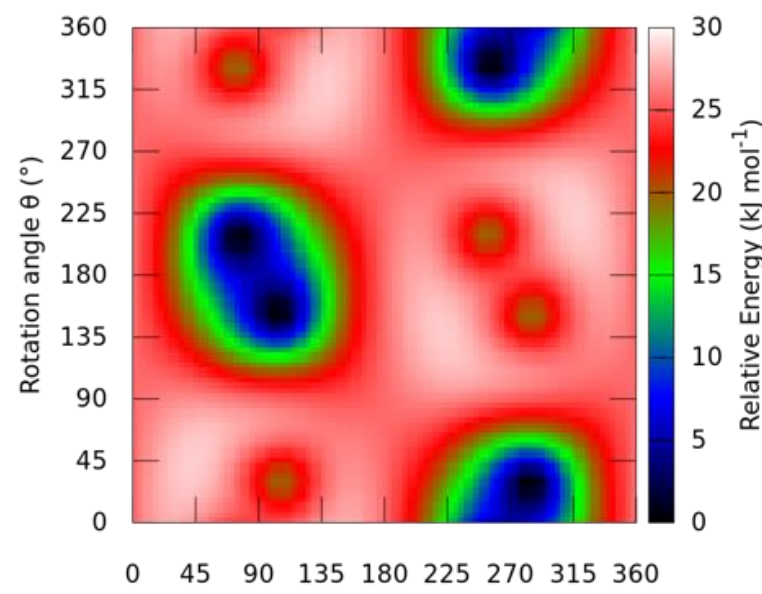

Rotation angle $\Psi\left(^{\circ}\right)$

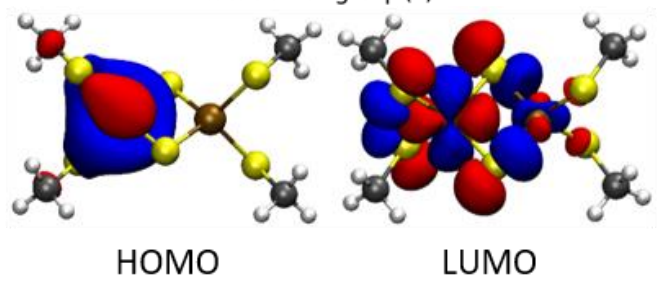

c)
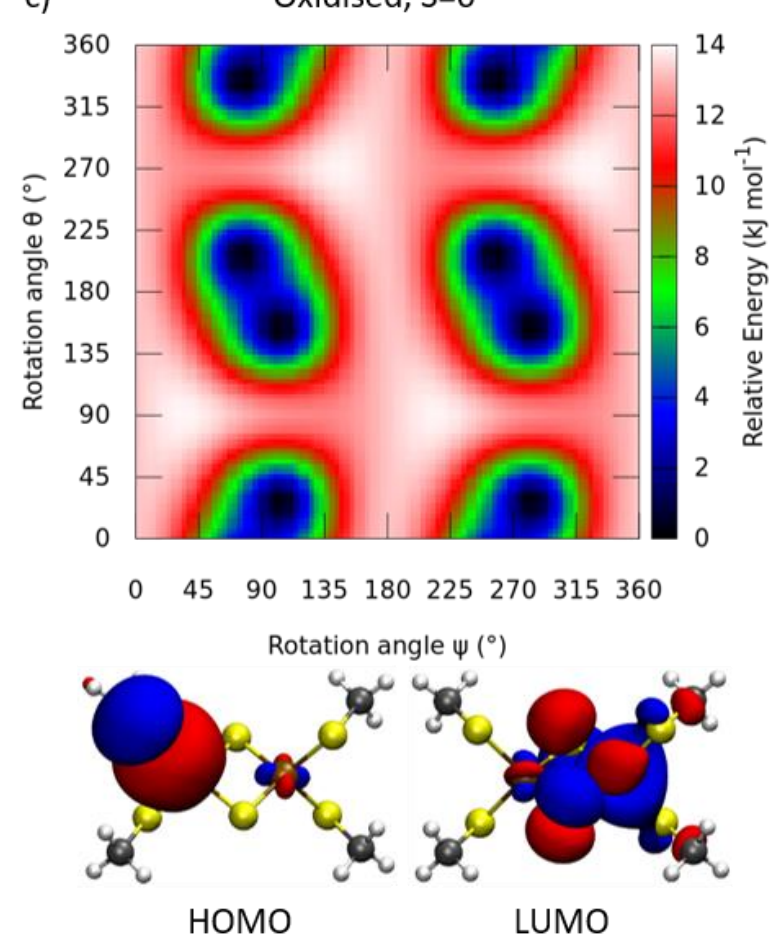

b)

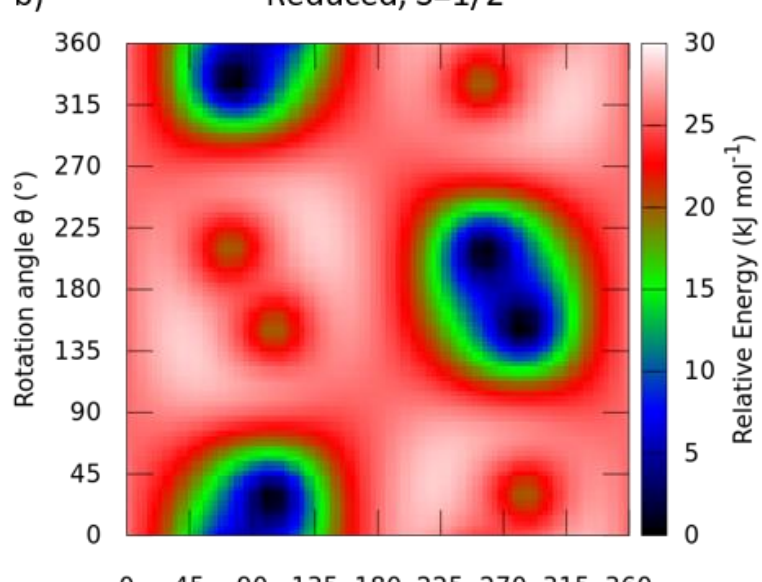

$04590 \quad 135180225 \quad 270315360$

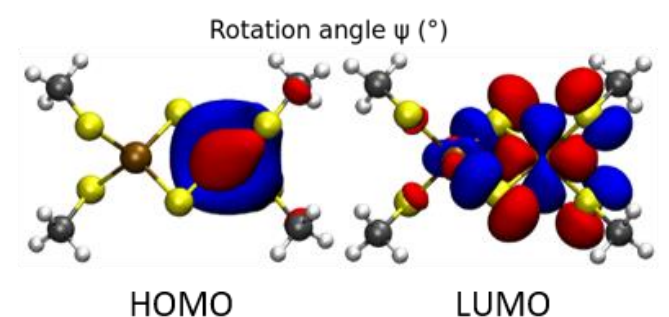

d)

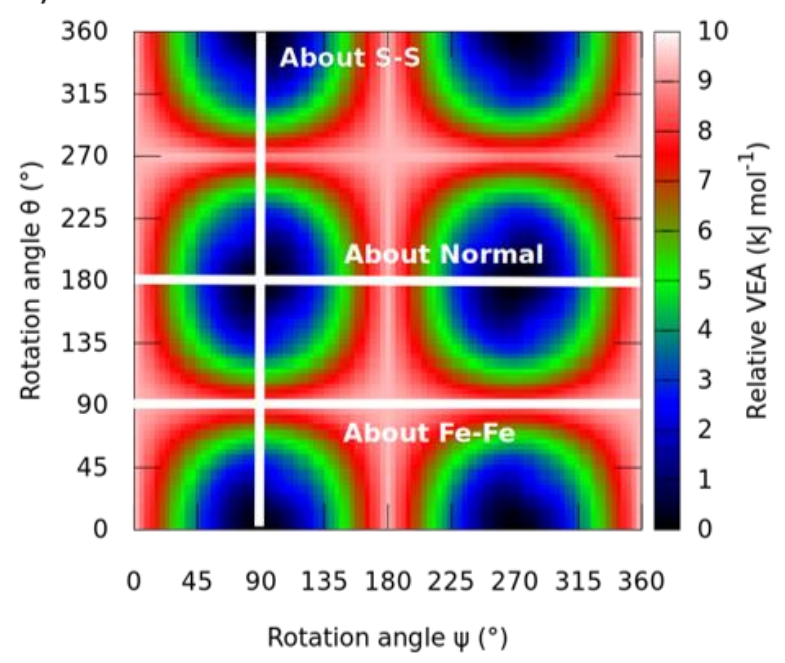

Figure 3: Frontier orbitals and effect of the three-dimensional rotation of an orientated electric field around the $2 \mathrm{Fe} 2 \mathrm{~S}$ cluster. a) Reduced, $\mathrm{S}=1 / 2$, Broken symmetry state 1 ; b) Reduced, $\mathrm{S}=1 / 2$, Broken symmetry state 2 ; c) Oxidised, $S=0$; d) Relative vertical electron affinity with most stable reduced broken symmetry state. 
The cubane cluster displays more complex features. While the $2 \mathrm{Fe} 2 \mathrm{~S}$ cluster showed clear symmetry for the oxidised state, and a clear asymmetry related to the positioning of the unpaired electron density in the reduced states, the $4 \mathrm{Fe} 4 \mathrm{~S}$ cluster appears to display similar patterns of stability regardless of oxidation or broken symmetry state. The magnitude of these patterns varies, however. The relative energy of the cubane clusters with respect to the rotation of the field is influenced by the location of the HOMO seen in Figures 4 and 5. The significant change in the location of electron density between these two broken symmetry states results in the quadrants containing the maxima and minima being reversed. The directions of the field that result in the greatest stability remain broadly the same between for these and the oxidised state. This suggests that the external electric field has a lower polarising effect on the $4 \mathrm{Fe} 4 \mathrm{~S}$ cluster compared to the $2 \mathrm{Fe} 2 \mathrm{~S}$ cluster and therefore a much lower effect on stability. Any of the four rotations where $\psi, \theta=90^{\circ}, 270^{\circ}$ show the largest degree of variation in relative energy. These rotations lie along two perpendicular internal quadrilateral planes of the cluster that are coincident with its edges. The maximum VEA difference observed for the electric field is $\Delta E_{V E A}=25.43 \mathrm{~kJ} \mathrm{~mol}^{-1}$.

The labile cubane cluster also shows only a difference in magnitude rather than location of the lowest energy orientation. There is a much less complex pattern for this molecule and, noting that the points at which the field is aligned along a vector passing through the edge created by the labile iron and a sulfur atom have the highest VEA, and a perpendicular vector has the lowest VEA, suggests that the effect of this labile iron atom is dominant. Here, the maximal influence of the electric field on the VEA is not along an axis involving the unique iron. The maximum electric field effect on the VEA observed for this cluster is $\Delta E_{V E A}=19.97 \mathrm{~kJ} \mathrm{~mol}^{-1}$. Previous work on similar ${ }^{89}$ and related ${ }^{90}$ structures shows that the values for the changes in VEA are both significant relative to the absolute VEA but not unreasonably high in magnitude. Notably these VEA values fall within the 0-0.51 eV $\left(0-49 \mathrm{~kJ} \mathrm{~mol}^{-1}\right)$ range of magnitudes predicted when varying surrounding and connected amino acids 
around iron-sulfur clusters. ${ }^{69}$ It is also of interest to note that the field vector resulting in the maximum and minimum values of relative VEA are the same for both the 4Fe4S and Labile 4Fe4S clusters, specifically approximately passing through a methyl group, the bonded sulfur and iron, and finally through the centre of the cube and through the opposite sulfur atom. Since the maxima and minima observed for the VEA also influence electron transfer reactions it is not surprising that the observed field vectors (for maxima and minima) also follow the direction of the initial reductive electron transfer necessary for the formation of the $5^{\prime}$-deoxyadenosyl radical in radical SAM enzymes. ${ }^{91}$ As rSAM enzymes share the common feature of SAM bound to the cluster this demonstrates how those enzymes may have evolved to arrange the active site to follow the minimum energy pathway for this initial activation step for the enzymes. Additional electrostatic field effects initiated by other charged residues nearby can either support or reduce this effect. 
a)

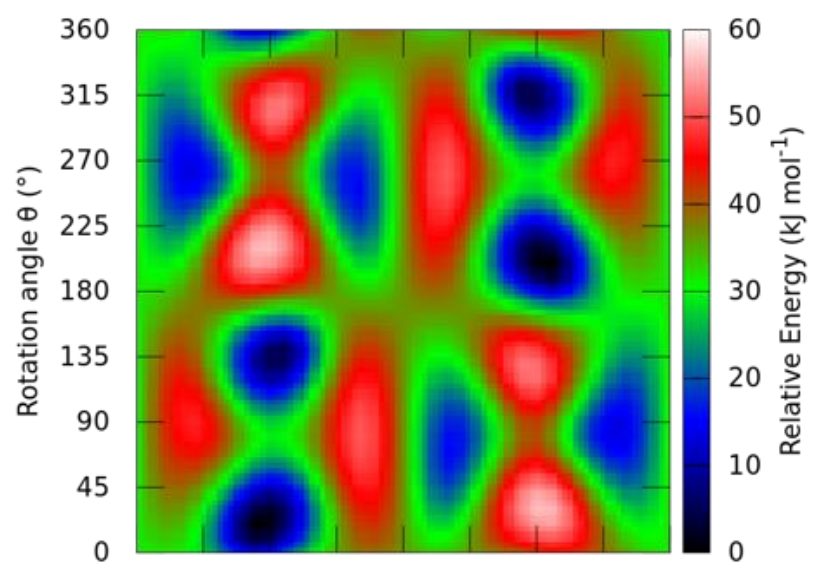

$\begin{array}{lllllllll}0 & 45 & 90 & 135 & 180 & 225 & 270 & 315 & 360\end{array}$

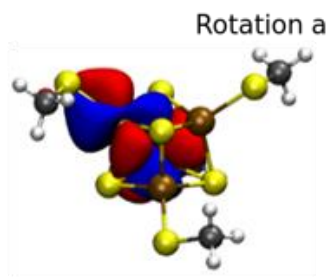

HOMO

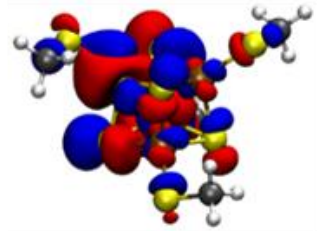

LUMO

c)
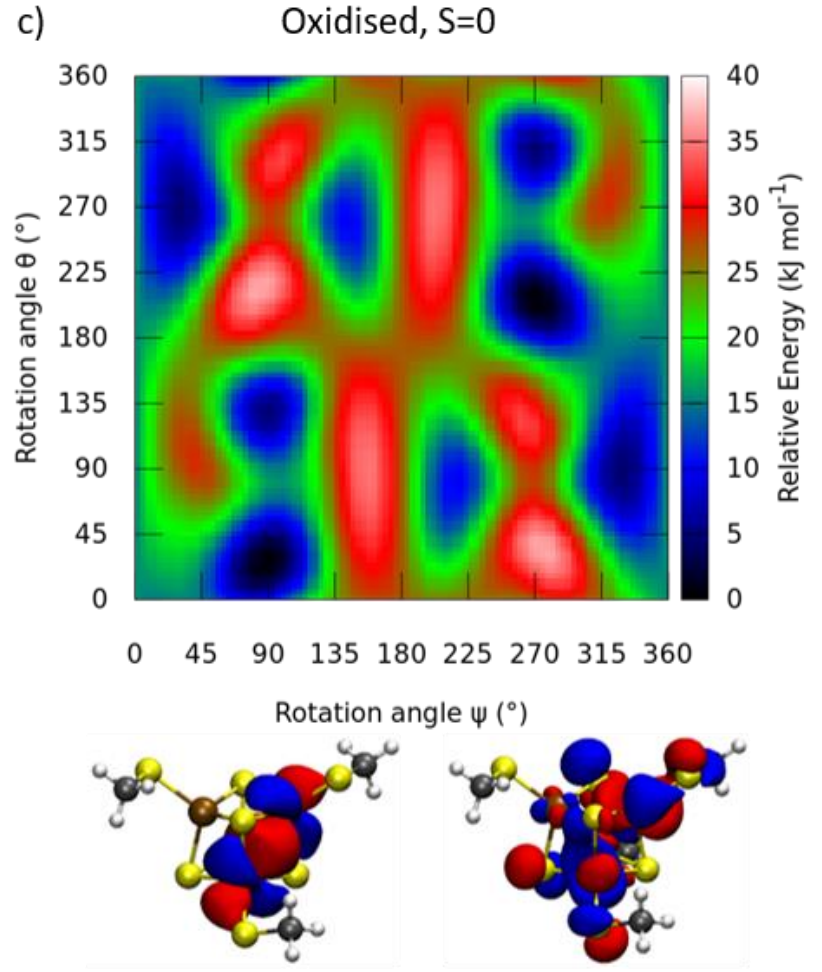

HOMO

b)

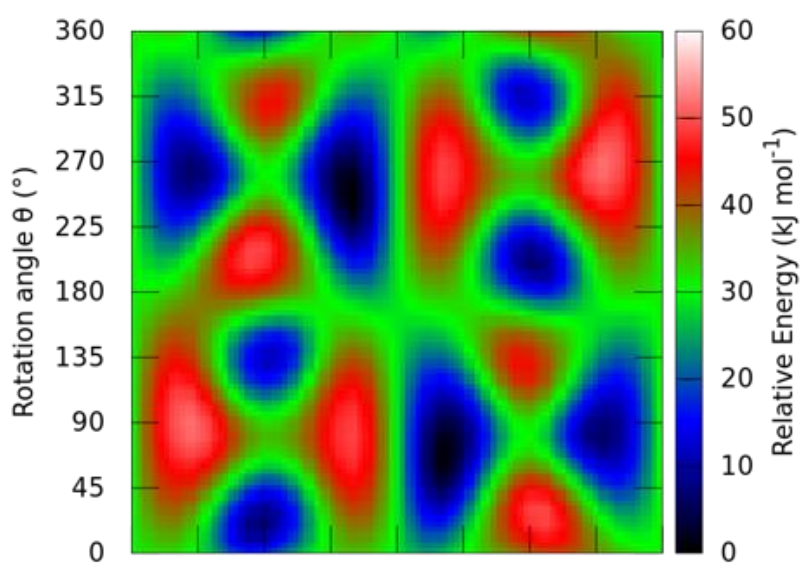

$0 \quad 45 \quad 90 \quad 135180225270315360$

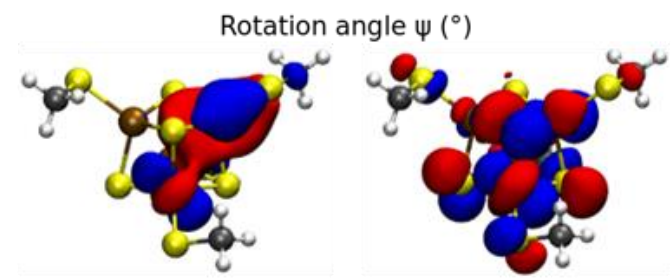

HOMO

LUMO

d)

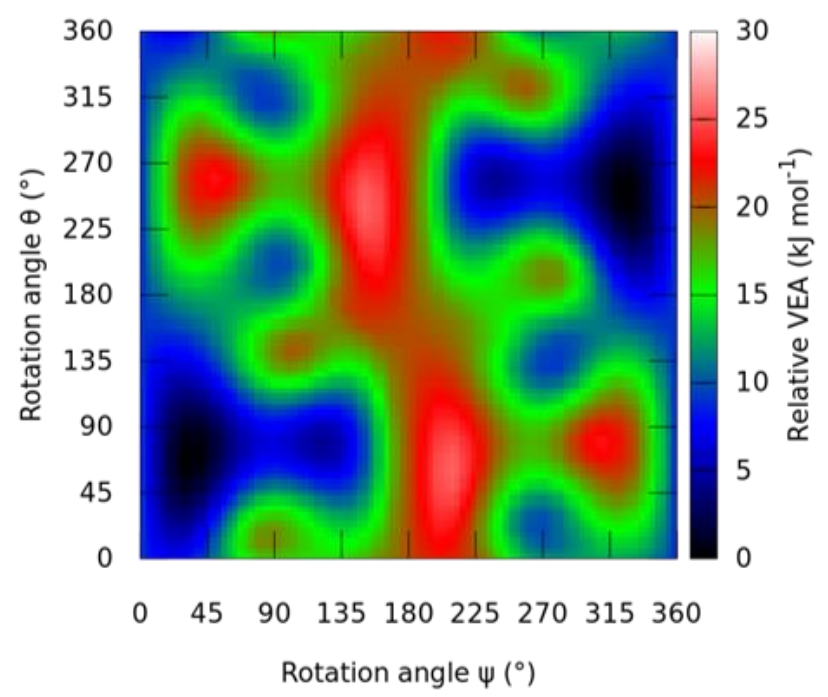

Figure 4: Frontier orbitals and effect of the three-dimensional rotation of an orientated electric field around the $4 \mathrm{Fe} 4 \mathrm{~S}$ cluster. a) Reduced, $S=1 / 2$, Broken symmetry state 3 ; b) Reduced, $S=1 / 2$, Broken symmetry state 4; c) Oxidised, $S=0$, Broken symmetry state 4; d) Relative vertical electron affinity with most stable reduced broken symmetry state. 


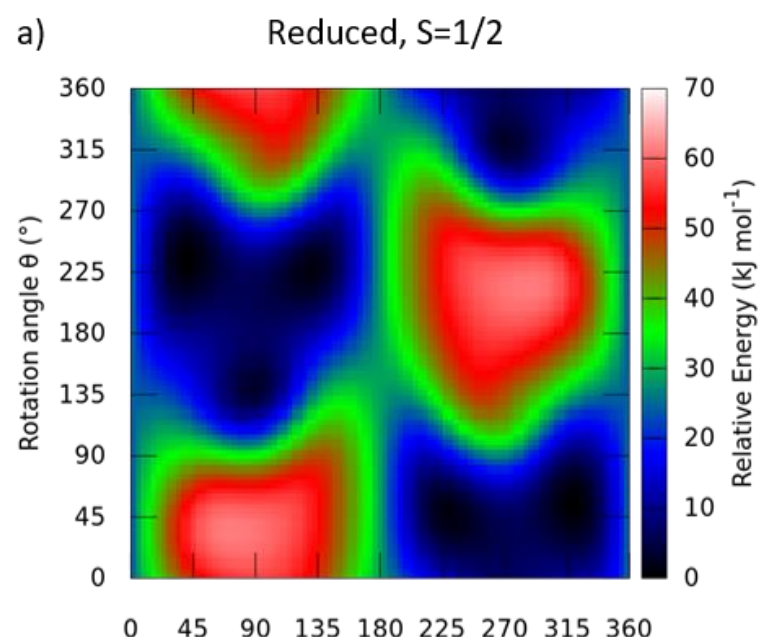
Rotation angle $\psi\left({ }^{\circ}\right)$

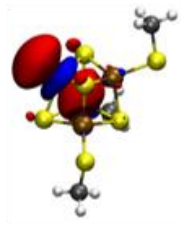

HOMO

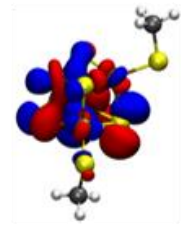

LUMO

c)

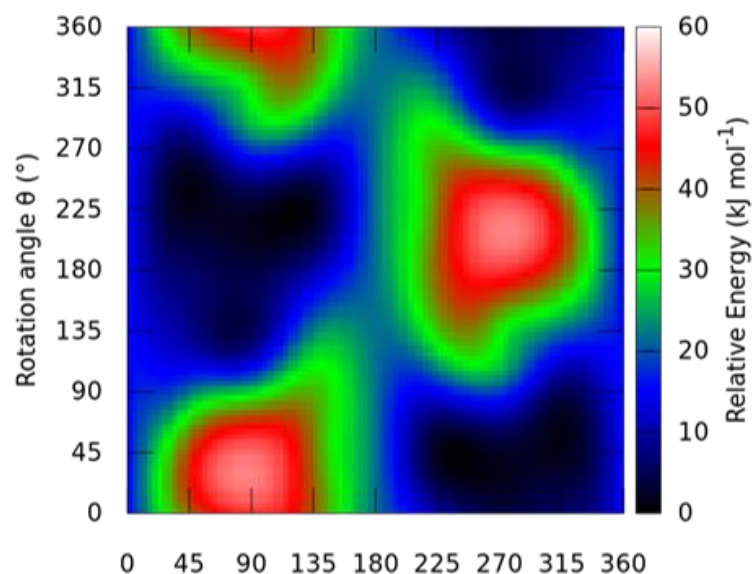

Rotation angle $\psi\left({ }^{\circ}\right)$

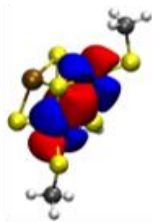

HOMO

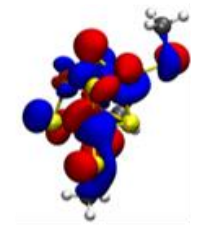

LUMO b)

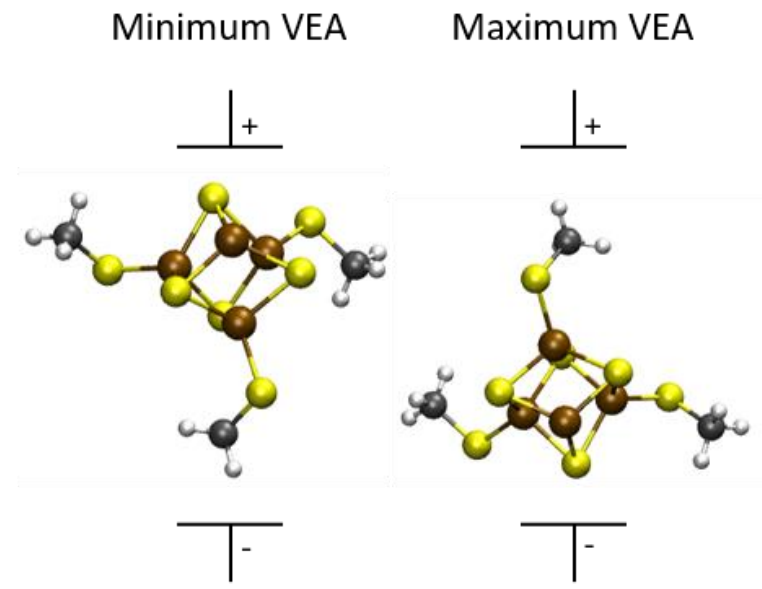

$\theta=140^{\circ} \Psi=280^{\circ} \quad \theta=140^{\circ} \Psi=100^{\circ}$

d)

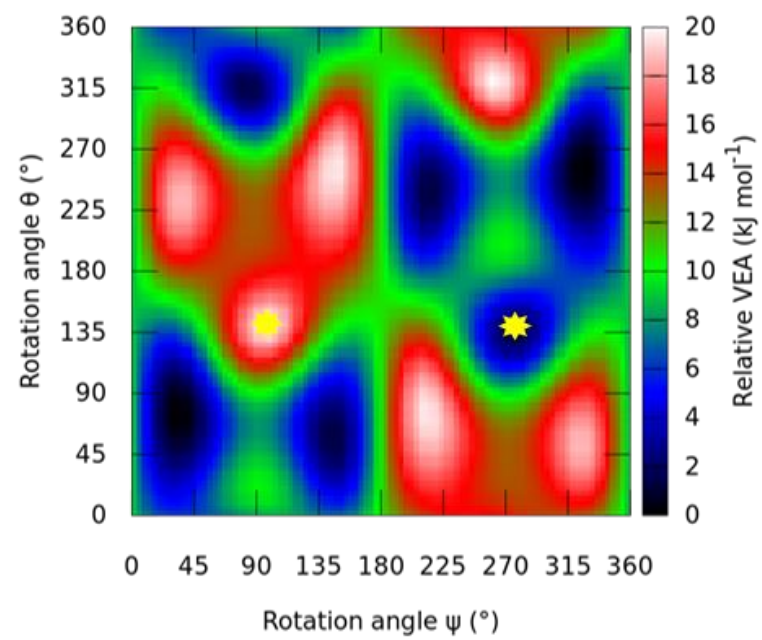

Figure 5: Frontier orbitals and effect of the three-dimensional rotation of an orientated electric field around the labile $4 \mathrm{Fe} 4 \mathrm{~S}$ cluster. a) Reduced, $\mathrm{S}=1 / 2$; b) Exemplary orientation of the field for the maximum and minimum values of the VEA, indicated in d) by a yellow asterisk; c) Oxidised, $\mathrm{S}=0$; d) Vertical electron affinity. 


\section{Conclusions}

We systematically investigated the effect of a rotating orientated electric field on the stability and reactivity of biologically relevant iron-sulfur clusters. Applying DFT calculations on the model clusters, we used the VEA - represented as the energy difference between oxidised and reduced state - as an indicator for the redox reactivity of the clusters. In both cases of pure gas phase and calculations in implicit solvent, we could show that a directed electric field induced by two distant point charges significantly influences the stability and reactivity of the clusters. In agreement with molecular frontier orbital theory, the effects are significantly different for different oxidation and broken symmetry states. This leads to the observation that the most stable broken symmetry state changes when re-orientating an electric field around the $2 \mathrm{Fe} 2 \mathrm{~S}$ cluster, with significant implication for the reactivity of such clusters in heterogeneous environments like enzyme active sites. Different orientations of the electric field had significantly different influences on the VEA and thus reactivity of the clusters with a maximum effect of up to $25.5 \mathrm{~kJ} \mathrm{~mol}^{-1}$

The cubane clusters display more complex behaviour with it still being clear that the external electric field has a dramatic effect on the stability and reactivity of these clusters. The introduction of the COSMO environment alters the stability of the reduced cluster, stabilising the favoured broken symmetry $1 / 2$ spin state relative to the other broken symmetry state, but also stabilising the $9 / 2$ state relative to the most favoured state, suggesting that in a protein environment this stabilisation effect is strengthened. The effects on the VEA are similar and in both cases dependent largely on whether the iron atoms are experiencing unique force field environments or similar ones, shown by Figure 2D, where the field is rotated about the Fe-Fe axis and the changes in orientation are therefore the same for both iron atoms. Comparing the field with the orbital occupation of the HOMO and LUMO of the 
clusters, reinforces the hypothesis that the spatial location of electron density contributes significantly to the observed effects.

These strong anisotropic effects of the electric fields demonstrate their relevance for ironsulfur clusters embedded in heterogeneous enzymatic environments. The impact of the field might explain how enzymes influence the redox reactivity of such clusters in a significant way. This systematic study reveals how these effects might be rationally explored and used as a powerful tool for enzyme engineering where the external electric field would be generated by surrounding residues, which can be mutated for direct control of the properties of the iron-sulfur clusters. The applications would include altering catalytic rate, substrate scope and cluster stability (for example in oxygen sensitive enzymes), and further work will focus on the nature and magnitude of these possible applications and how generalisable this is to other similar molecular groups in enzymes.

\section{Acknowledgements}

The authors thank the EPSRC Centre for Doctoral Training in Sustainable Chemistry (EP/L015633/1) for support and we are grateful for access to the University of Nottingham High Performance Computing Facility. JH is supported by the Royal Academy of Engineering under the Chairs in Emerging Technologies scheme.

\section{References}

1 Huber, C.; Wächtershäuser, G. Activated acetic acid by carbon fixation on (Fe,Ni)S under primordial conditions. Science. 1997, 276, 245-247.

2 Beinert, H.; Holm, R. H.; Münck, E. Iron-sulfur clusters: nature's modular, multipurpose structures. Science (New York, N.Y.) 1997, 277, 653-659. 
3 Beinert, H. Iron-sulfur proteins: ancient structures, still full of surprises. J. Biol. Inorg. Chem. 2000, 5, 2-15.

4 Johnson, D. C.; Dean, D. R.; Smith, A. D.; Johnson, M. K. Structure, function, and formation of biological iron-sulfur clusters. Annu. Rev. Biochem. 2005, 74, 247-281.

5 Mortenson, L. E.; Valentine, R. C.; Carnahan, J. E. An electron transport factor from Clostridiumpasteurianum. Biochem. Biophys. Res. Commun. 1962, 7, 448-452.

6 Glaser, T.; Hedman, B.; Hodgson, K. O.; Solomon, E. I. Ligand K-edge X-ray absorption spectroscopy: a direct probe of ligand-metal covalency. Acc. Chem. Res. 2000, 33, 859-868. 7 Noodleman, L.; Case, D. A. Density-Functional Theory of Spin Polarization and Spin Coupling in Iron-Sulfur Clusters. In Iron-Sulfur Proteins; Advances in Inorganic Chemistry 38; Academic Press, Inc: San Diego, CA, 1992; pp 424-467.

8 Lubitz, W.; Ogata, H.; Rüdiger, O.; Reijerse, E. Hydrogenases. Chem. Rev. 2014, 114, 40814148.

9 Peters, J. W.; Stowell, M. H.; Soltis, S. M.; Finnegan, M. G.; Johnson, M. K.; Rees, D. C. Redoxdependent structural changes in the nitrogenase P-cluster. Biochemistry. 1997, 36, 1181-1187.

10 Cheek, J.; Broderick, J.B. Adenosylmethionine-dependent iron-sulfur enzymes: versatile clusters in a radical new role. J. Biol. Inorg. Chem. 2001, 6, 209-226.

11 Broderick, J. B.; Duffus, B. R.; Duschene, K. S.; Shepard, E. M. Radical S-Adenosylmethionine Enzymes. Chem. Rev. 2014, 114, 4229-4317.

12 Radical SAM Enzymes. In Methods in Enzymology; Bandarian, V., Ed.; Academic Press, Elsevier, 2018; Vol. 606

13 Jäger, C. M.; Croft, A. K. Anaerobic Radical Enzymes for Biotechnology. ChemBioEng Rev. 2018, $5,143-162$. 
14 Fugate, C. J.; Jarrett, J. T. Biotin synthase: Insights into radical-mediated carbon-sulfur bond formation. Biochim. Biophys. Acta, Proteins Proteomics. 2012, 1824, 1213-1222.

15 Wood, Z. A.; Schröder, E.; Harris, J. R.; Poole, L. B. Structure, mechanism and regulation of peroxiredoxins. Trends Biochem. Sci. 2003, 28, 32-40.

16 Arnér, E. S. J.; Holmgren, A Physiological functions of thioredoxin and thioredoxin reductase. Eur. J. Biochem. 2001, 267, 6102-6109.

17 Tsukamoto, Y.; Fukushima, Y.; Hara, S.; Hisabori, T. Redox Control of the Activity of Phosphoglycerate Kinase in Synechocystis sp. PCC6803. Plant and Cell Physiol. 2013, 54, 484491.

18 Gilbert, H. F.; Redox control of enzyme activities by thiol/disulfide exchange. In Methods in Enzymology; Academic Press, Elsevier, 1984; Vol. 107, pp 330-351.

19 Richter, A. S.; Grimm, B. Thiol-based redox control of enzymes involved in the tetrapyrrole biosynthesis pathway in plants. Front. Plant Sci. 2013, 4, 371.

20 Hitaishi, V. P.; Clement, R.; Bourassin, N.; Baaden, M.; De Poulpiquet, A.; Sacquin-Mora, S.; Ciaccafava, A.; Lojou, E. Controlling Redox Enzyme Orientation at Planar Electrodes. Catalysts. 2018, 8, 192.

21 Caceres, T. B.; Price, O.; Morales, Y.; Hevel, J. Redox Control of PRMT1 Substrate Specificity. FASEB J. 2017, 31, 765.11.

22 Bonifacio, A.; Millo, D.; Keizers, P. H. J.; Boegschoten, R.; Commandeur, J. N. M.; Vermeulen, N. P. E.; Gooijer, C.; van der Zwan, G. Active-site structure, binding and redox activity of the heme-thiolate enzyme CYP2D6 immobilized on coated Ag electrodes: a surface-enhanced resonance Raman scattering study. JBIC, J. Biol. Inorg. Chem. 2008, 13, 85-96. 
23 Skryhan, K.; Cuesta-Seijo, J. A.; Nielsen, M. M.; Marri, L.; Mellor, S. B.; Glaring, M. A.; Jensen, P. E.; Palcic, M. M.; Blennow, A. The Role of Cysteine Residues in Redox Regulation and Protein Stability of Arabidopsis thaliana Starch Synthase 1. PloS One. 2015, 10, e0136997. 24 Leger, C.; Bertrand, P. Direct Electrochemistry of Redox Enzymes as a Tool for Mechanistic Studies. Chem. Rev. 2008, 108, 2379-2438.

25 Gates, A. J.; Kemp, G. L.; To, C. Y.; Mann, J.; Marritt, S. J.; Mayes, A. G.; Richardson, D. J.; Butt, J. N. The relationship between redox enzyme activity and electrochemical potential-cellular and mechanistic implications from protein film electrochemistry. Phys. Chem. Chem. Phys. 2011, $13,7720-7731$.

26 Elliott. S. J.; Léger, C.; Pershad, H.R.; Hirst, J.; Heffron, K.; Ginet, N.; Blasco, F.; Rothery, R. A.; Weiner, J. H.; Armstrong, F. A. Detection and interpretation of redox potential optima in the catalytic activity of enzymes. Biochim. Biophys. Acta. 2002, 1555, 54-59.

27 Tran, K. N.; Niu, S.; Ichiye, T. Reduction Potential Calculations of the Fe-S Clusters in Thermus thermophilus Respiratory Complex I. J. Comput. Biol. 2019, 40, 1248-1256.

28 Bak, D. W.; Elliott, S. J. Alternative FeS cluster ligands: tuning redox potentials and chemistry. Curr. Opin. Chem. Biol. 2014, 19, 50-58.

29 Zhang, L.; Cui, H.; Zou, Z.; Garakani, T. M.; Novoa-Henriquez, C.; Jooyeh, B.; Schwaneberg, U. Directed Evolution of a Bacterial Laccase (CueO) for Enzymatic Biofuel Cells. Angew. Chem., Int. Ed. 2019, 58, 4562-4565.

30 Sandford, C.; Edwards, M. A.; Klunder, K. J.; Hickey, D. P.; Li, M.; Barman, K.; Sigman, M. S.; White, H. S.; Minteer, S. D. A synthetic chemist's guide to electroanalytical tools for studying reaction mechanisms. Chem. Sci. 2019, 10, 6404-6422. 
31 Hannemann, F.; Guyot, A.; Zöllner, A.; Müller, J. J.; Heinemann, U.; Bernhardt, R. The dipole moment of the electron carrier adrenodoxin is not critical for redox partner interaction and electron transfer. J. Inorg. Biochem. 2009, 103, 997-1004.

32 Ikeda, T.; Kano, K. An electrochemical approach to the studies of biological redox reactions and their applications to biosensors, bioreactors, and biofuel cells. J. Biosci. Bioeng. 2001, 92, 9-18. 33 Warshel, A.; Aqvist, J. Electrostatic Energy and Macromolecular Function. Annu. Rev. Biophys. Biophys. Chem. 1991, 20, 267-298.

34 Sheinerman, F. B.; Norel, R.; Honig, B. Electrostatic aspects of protein-protein interactions. Curr. Opin. Struct. Biol. 2000, 10, 153-159.

35 Hanoian, P.; Liu, T.; Hammes-Schifffer, S.; Benkovic, S. Perspectives on Electrostatics and Conformational Motions in Enzyme Catalysis. Acc. Chem. Res. 2015, 48, 482-489.

36 Warshel, A.; Sharma, P. K.; Kato, M.; Xiang, Y.; Liu, H.; Olsson, M. H. M. Electrostatic Basis for Enzyme Catalysis. Chem. Rev. 2006, 106, 3210-3235.

37 Fried, S. D.; Boxer, S. G. Electric Fields and Enzyme Catalysis. Annu. Rev. Biochem. 2017, 86, $387-415$.

38 Warshel, A. Electrostatic Origin of the Catalytic Power of Enzymes and the Role of Preorganized Active Sites. J. Biol. Chem. 1998, 273, 27035-27038.

39 Morgenstern, A.; Jaszai, M.; Eberhart, M. E.; Alexandrova, A. N. Quantified electrostatic preorganization in enzymes using the geometry of the electron charge density. Chem. Sci. 2017, 8 , 5010-5018.

40 Fuller, J.; Wilson, T. R.; Eberhart, M. E.; Alexandrova, A. N. Charge Density in Enzyme Active Site as a Descriptor of Electrostatic Preorganization. J. Chem. Inf. Model. 2019, 59, 2367-2373. 41 Náray-Szabó, G. Electrostatic catalysis in enzymes. J. Mol. Catal. 1988, 47, 281-287. 
42 Warshel, A. Computer Simulations of Enzyme Catalysis: Methods, Progress, and Insights. Annu. Rev. Biophys. Biomol. Struct. 2003, 32, 425-443.

43 Warshel, A.; Sharma, P. K.; Kato, M.; Parson, W. W. Modeling electrostatic effects in proteins. Biochim. Biophys. Acta. 2006, 1764, 1647-1676.

44 Nielsen, J. E.; Beier, L.; Otzen, D.; Borchert, T. V.; Frantzen, H. B.; Andersen, K. V.; Svendsen, A. Electrostatics in the active site of an $\alpha$-amylase. Eur. J. Biochem. 1999, 264, 816-824. 45 Yang, Z.; Liu, F.; Steeves, A. H. and Kulik, H. J. Quantum Mechanical Description of Electrostatics Provides a Unified Picture of Catalytic Action Across Methyltransferases. J. Phys. Chem. Lett. 2019, 10, 3779-3787.

46 Suess, C. J.; Martins, F. L.; Croft, A. K.; Jäger, C. M. Radical Stabilization Energies for Enzyme Engineering: Tackling the Substrate Scope of the Radical Enzyme QueE. J. Chem. Inf. Model. 2019, 59, 5111-5125.

47 Gilson, M. K.; Honig, B. H. Calculation of electrostatic potentials in an enzyme active site. Nature 1987, 330, 84-86.

48 Eun, C.; Kekenes-Huskey, P. M.; Metzger, V. T.; McCammon, J. A. A model study of sequential enzyme reactions and electrostatic channeling. J. Chem. Phys. 2014, 140, 105101. 49 Wade, R. C.; Gabdoulline, R. R.; Lüdemann, S. K.; Lounnas, V. Electrostatic steering and ionic tethering in enzyme-ligand binding: Insights from simulations. Proc. Natl. Acad. Sci. U. S. A. 1998, 95, 5942-5949.

50 Fried, S. D.; Bagchi, S.; Boxer, S. G. Extreme electric fields power catalysis in the active site of ketosteroid isomerase. Science. 2014, 346, 1510-1514.

51 Shaik, S.; Mandal, D.; Ramanan, R. Oriented electric fields as future smart reagents in chemistry. Nat. Chem. 2016, 8, 1091-1098. 
52 Orozco-Gonzalez, Y.; Kabir, M. P.; Gozem, S. Electrostatic Spectral Tuning Maps for Biological Chromophores. J. Phys. Chem. B. 2019, 123, 4813-4824.

53 Prah, A.; Frančišković, E.; Mavri, J.; Stare, J. Electrostatics as the Driving Force Behind the Catalytic Function of the Monoamine Oxidase A Enzyme Confirmed by Quantum Computations. ACS Catal. 2019, 9, 1231-1240.

54 Bhave, D. P.; Han, WG.; Pazicni, S.; Penner-Hahn, J. E.; Carroll, K. S.; Noodleman, L. Geometric and Electrostatic Study of the [4Fe-4S] Cluster of Adenosine-5'-Phosphosulfate Reductase from Broken Symmetry Density Functional Calculations and Extended X-ray Absorption Fine Structure Spectroscopy. Inorg. Chem. 2011, 50, 6610-6625.

55 Noodleman, L. Valence bond description of antiferromagnetic coupling in transition metal dimers. J. Chem. Phys. 1981, 74, 5737-5743.

56 Y. Shao, Z. Gan, E. Epifanovsky, A. T. B. Gilbert, M. Wormit, J. Kussmann, A. W. Lange, A. Behn, J. Deng, X. Feng, D. Ghosh, M. Goldey P. R. Horn, L. D. Jacobson, I. Kaliman, R. Z. Khaliullin, T. Kús, A. Landau, J. Liu, E. I. Proynov, Y. M. Rhee, R. M. Richard, M. A. Rohrdanz, R. P. Steele, E. J. Sundstrom, H. L. Woodcock III, P. M. Zimmerman, D. Zuev, B. Albrecht, E. Alguire, B. Austin, G. J. O. Beran, Y. A. Bernard, E. Berquist, K. Brandhorst, K. B. Bravaya, S. T. Brown, D. Casanova, C.-M. Chang, Y. Chen, S. H. Chien, K. D. Closser, D. L. Crittenden, M. Diedenhofen, R. A. DiStasio Jr., H. Dop, A. D. Dutoi, R. G. Edgar, S. Fatehi, L. Fusti-Molnar, A. Ghysels, A. Golubeva-Zadorozhnaya, J. Gomes, M. W. D. Hanson-Heine, P. H. P. Harbach, A. W. Hauser, E. G. Hohenstein, Z. C. Holden, T.-C. Jagau, H. Ji, B. Kaduk, K. Khistyaev, J. Kim, J. Kim, R. A. King, P. Klunzinger, D. Kosenkov, T. Kowalczyk, C. M. Krauter, K. U. Lao, A. Laurent, K. V. Lawler, S. V. Levchenko, C. Y. Lin, F. Liu, E. Livshits, R. C. Lochan, A. Luenser, P. Manohar, S. F. Manzer, S.-P. Mao, N. Mardirossian, A. V. Marenich, S. A. Maurer, N. J. Mayhall, C. M. Oana, R. Olivares-Amaya, D. P. O’Neill, J. A. Parkhill, T. M. Perrine, R. Peverati, 
P. A. Pieniazek, A. Prociuk, D. R. Rehn, E. Rosta, N. J. Russ, N. Sergueev, S. M. Sharada, S.

Sharmaa, D. W. Small, A. Sodt, T. Stein, D. Stück, Y.-C. Su, A. J. W. Thom, T. Tsuchimochi, L. Vogt, O. Vydrov, T. Wang, M. A. Watson, J. Wenzel, A. White, C. F. Williams, V. Vanovschi, S. Yeganeh, S. R. Yost, Z.-Q. You, I. Y. Zhang, X. Zhang, Y. Zhou, B. R. Brooks, G. K. L. Chan, D. M. Chipman, C. J. Cramer, W. A. Goddard III, M. S. Gordon, W. J. Hehre, A. Klamt, H. F. Schaefer III, M. W. Schmidt, C. D. Sherrill, D. G. Truhlar, A. Warshel, X. Xua, A. Aspuru-Guzik, R. Baer, A. T. Bell, N. A. Besley, J.-D. Chai, A. Dreuw, B. D. Dunietz, T. R. Furlani, S. R.

Gwaltney, C.-P. Hsu, Y. Jung, J. Kong, D. S. Lambrecht, W. Liang, C. Ochsenfeld, V. A. Rassolov, L. V. Slipchenko, J. E. Subotnik, T. Van Voorhis, J. M. Herbert, A. I. Krylov, P. M. W. Gill, and M. Head-Gordon. Advances in molecular quantum chemistry contained in the Q-Chem 4 program package. Mol. Phys. 2015, 113, 184-215.

57 Carvalho, A. T.; Swart, M. Electronic structure investigation and parametrization of biologically relevant iron-sulfur clusters. J. Chem. Inf. Model. 2014, 54, 613-620.

58 Swart, M.; Groenhof, A. R.; Ehlers, A. W.; Lammerstsma, K. Validation of Exchange-Correlation Functionals for Spin States of Iron Complexes. J. Phys. Chem. A. 2004, 108, $5479-5483$.

59 Swart, M.; Ehlers, A. W.; Lammertsma, K. Performance of the OPBE exchange-correlation functional. Mol. Phys. 2004, 102, 2467-2474.

60 Handy, N. C.; Cohen, A. J. Left-right correlation energy. Mol. Phys. 2000, 99, 403-412.

61 Perdew, J. P.; Burke, K. Ernzerhof, M. Generalized Gradient Approximation Made Simple. Phys. Rev. Lett. 1996, 77, 3865.

62 Swart, M.; Groenhof, A. R.; Ehlers, A. W.; Lammertsma, K. Validation of Exchange-Correlation Functionals for Spin States of Iron Complexes. J. Phys. Chem. A. 2004, 108, $5479-5483$. 
63 Swart, M.; Ehlers, A. W.; Lammertsma, K. Performance of the OPBE exchange-correlation functional. Mol. Phys. 2004, 102, 2467-2474.

64 Van Lenthe, E.; Baerends, E. J. Optimized Slater-type basis sets for the elements 1-118. J. Comput. Chem. 2003, 24, 1142-1156.

65 Chong, D. P.; Van Lenthe, E.; Van Gisbergen, S.; Baerends, E. J. Even-tempered slater-type orbitals revisited: From hydrogen to krypton. J. Comput. Chem. 2004, 25, 1030-1036.

66 Chong, D. P. Augmenting basis set for time-dependent density functional theory calculation of excitation energies: Slater-type orbitals for hydrogen to krypton. Mol. Phys. 2005, 103, 749-761. 67 Harris, T. V.; Szilagyi, R. K.; Iron-Sulfur Bond Covalency from Electronic Structure Calculations for Classical Iron-Sulfur Clusters. J. Comput. Chem. 2014, 35, 540-552.

68 Szilagyi, R. K.; Winslow, M. A.; On the Accuracy of Density Functional Theory for IronSulfur Clusters. J. Comput. Chem. 2006, 27, 1385-1397.

69 Harris, T. V.; Szilagyi, R. K.; Protein Environmental Effects on Iron-Sulfur Clusters: A Set of Rules for Constructing Computational Models for Inner and Outer Coordination Spheres. $J$.

Comput. Chem. 2016, 37, 1681-1696.

70 Swart, M. Accurate spin-state energies for iron complexes. J. Chem. Theory Comput. 2008, 4, 2057-2066.

71 Güell, M.; Luis, J. M.; Solà, M.; Swart, M. Importance of the basis set for the spin-state energetics of iron complexes. J. Phys. Chem. A. 2008, 112, 6384-6391.

72 Klamt, A.; Schüürmann, G. COSMO: a new approach to dielectric screening in solvents with explicit expressions for the screening energy and its gradient. J. Chem. Soc., Perkin Trans. 2. 1993, 799-805.

73 Gilson, M. K.; Honig, B. H. The dielectric constant of a folded protein. Biopolymers. 1986, 25, 2097-2119. 
74 Sharp, K. A.; Honig, B. Electrostatic interactions in macromolecules: theory and applications. Annu. Rev. Biophys. Biophys. Chem. 1990, 19, 301-332.

75 Noodleman, L.; Baerends, E. J. Electronic Structure, Magnetic Properties, ESR, and Optical Spectra for 2-Fe Ferredoxin Models by LCAO-Xa Valence Bond Theory. J. Am. Chem. Soc. 1984, 106, 2316-2327.

76 Noodleman, L.; Peng, C. Y.; Case, D. A.; Mouesca, J.-M. Orbital interactions, electron delocalization and spin coupling in iron-sulfur clusters. Coordin. Chem. Rev. 1995, 144, 199-244. 77 Emel’yanova, N. S; Poleshchuk, O. Kh.; Sanina, N. A.; Aldoshin, S. M. Quantum chemical modelling of ligand substitution in cationic nitrosyl complexes. Russ. Chem. Bull., Int. Ed. 2014, 63, 1088-1094.

78 Sandala, G. M.; Hopmann, K. H.; Ghosh, A.; Noodleman, L. Calibration of DFT Functionals for the Prediction of ${ }^{57} \mathrm{Fe}$ Mossbauer Spectral Parameters in Iron-Nitrosyl and Iron-Sulfur Complexes: Accurate Geometries Prove Essential. J. Chem. Theory. Comput. 2011, 7, 3232-3247.

79 Jensen, K. P.; Ooi, B.-L.; Christensen, E. M. Accurate Computation of Reduction Potentials of 4Fe-4S Clusters Indicates a Carboxylate Shift in Pyrococcus furiosus Ferredoxin. Inorg. Chem. 2007, 46, 8710-8716.

80 Han, W.-G.; Liu, T.; Lovell, T.; Noodleman, L. Active Site Structure of Class I Ribonucleotide Reductase Intermediate X: A Density Functional Theory Analysis of Structure, Energetics, and Spectroscopy. J. Am. Chem. Soc. 2005, 127, 15778-15790.

81 Maiocco, S. J.; Walker, L. M.; Elliott, S. J. Determining Redox Potentials of the Iron-Sulfur Clusters of the AdoMet Radical Enzyme Superfamily. In Methods in Enzymology; Bandarian, V., Ed.; Academic Press, 2018; pp 319-339.

82 Bak, D. W.; Elliot, S. J. Alternative FeS cluster ligands: tuning redox potentials and chemistry. Curr. Opin. Chem. Biol. 2014, 19, 50-58. 
83 Miranda-Quintana, R. A.; González, M. M.; Ayers, P. W. Electronegativity and redox reactions. Phys. Chem. Chem. Phys. 2016, 18, 22235-22243.

84 Parr, R. G.; Szentpály, L. v.; Liu, Shubin. Electrophilicity Index. J. Am. Chem. Soc. 1999, 121, 1922-1924.

85 Moens, J.; Roos, G.; Jaque, P.; De Proft, F.; Geerlings, P. Can Electrophilicity Act as a Measure of the Redox Potential of First-Row Transition Metal Ions? Chem. Eur. J. 2007, 13, 9331-9343. 86 Chattaraj, P. K.; Giri, S. Electrophilicity index withing a conceptual DFT framework. Annu. Rep. Prog. Chem. Sect. C. 2009, 105, 13-39.

87 Moens, J.; Jaque, P.; De Proft, F.; Geerlings, P. The Study of Redox Reactions on the Basis of Conceptual DFT Principles: EEM and Vertical Quantities. J. Phys. Chem. A. 2008, 112, 6023-6031. 88 Roos, G.; Geerlings, P.; Messens, J. Enzymatic Catalysis: The Emerging Role of Conceptual Density Functional Theory. J. Phys. Chem. B. 2009, 113, 13465-13475.

89 Teo, R. D.; Rousseau, B. J. G.; Smithwick, E. R.; Di Felice, R.; Beratan, D. N.; Migliore, A. Charge Transfer between [4Fe4S] Proteins and DNA Is Unidirectional: Implications for Biomolecular Signaling. Chem. 2019, 5, 122-137.

90 Cervantes-Salguero, K.; Seminario, J. M. Structure and energetics of small iron clusters. J. Mol. Model. 2012, 18, 4043-4052.

91 Nicolet, Y.; Amara, P.; Mouesca, J.-M.; Fontecilla-Camps, J. C. Unexpected electron transfer mechanism upon AdoMet cleavage in radical SAM proteins. P. Natl. Acad. Sci. USA. 2009, 106, 14867-14871. 